\title{
Projeto SOS Português \& Aldeias Infantis: Português como língua de acolhimento no interior do Rio Grande do Norte
}

Márcia Oliveira ${ }^{1}$

RESUMO: Com a recente onda de entrada de imigrantes refugiados no Brasil, surgiu nos últimos anos neste país um processo pelo qual a língua portuguesa passou a ser necessidade de várias pessoas que aqui vieram pedir asilo ou refúgio. Neste trabalho queremos mostrar através de um breve relato a realização de um curso de português como língua de acolhimento oferecido a um grupo de refugiados venezuelanos acolhidos pela ONG SOS Aldeias Infantis em Caicó/RN. Nosso principal objetivo será mostrar alguns dos métodos e atividades usadas além das principais dificuldades encontradas nesta ação. Para Gomes de Matos (2014), professores podem praticar simples ações positivas que os transformem em agentes humanizadores, tais como conhecer as histórias, expectativas e desejos dos seus alunos. Tomando como base esta Linguística da Paz, é como mostraremos como a dimensão afetiva dos seres discursivos envolvidos no processo tiveram um rol importante para o sucesso deste projeto.

PALAVRAS-CHAVE: Português como língua de acolhimento; Linguística da Paz Aplicada; Projeto SOS Português e Aldeias Infantis.

\section{Portuguese as a host language in the interior of Rio Grande do Norte: SOS Português \& Aldeias Infantis.}

\begin{abstract}
With the recent influx of immigrant refugees in Brazil a process has emerged in recent years in which the Portuguese language has become a necessity for several people who have come here to seek asylum or refuge. In this paper, we would like to show a brief summary of a Portuguese course as a host language offered to a group of Venezuelan refugees hosted by the NGO SOS Aldeias Infantis in Caicó / RN. Our main goal will be to show some of the methods and activities used in addition to the main difficulties encountered in this action. For Gomes de Matos (2014), teachers can practice simple positive actions that transform them into humanizing agents, such as knowing the stories, expectations and desires of their students. Based on this Linguistic of Peace, it is how we will show how the affective dimension of the discursive beings involved in the process had an important role for the success of this project.
\end{abstract}

KEY WORDS: Portuguese as host language; Peace Linguistics; Portuguese SOS and Children's Villages.

\footnotetext{
${ }^{1}$ Universidade Federal do Rio Grande do Norte
} 


\section{INTRODUÇÃO:}

$\mathrm{Na}$ nossa atualidade parecem ser cada vez mais frequentes os fluxos migratórios. Seja a procura de trabalho, procurando melhores condições de vida ou até mesmo fugindo da guerra e da fome, a imigração de pessoas ao redor do mundo passa a ser uma realidade a qual se exige tanto dos cidadãos que migram como também daqueles cidadãos que acolhem os que chegam às suas terras.

O Brasil se tornou, na última década, ponto de chegada de povos de línguas e culturas tão diversas quanto distantes uma das outras, mas que compartilham de uma mesma necessidade: uma terra que os acolha com trabalho e segurança. São haitianos fugindo de um terremoto ocorrido em 2010, nigerianos perseguidos por milícias terroristas como o Boko Haram, sírios expatriados de sua nação, em guerra desde 2011, e acuados pelo autodenominado Estado Islâmico, congoleses vindos de um território dividido em dois países por conflitos violentos, colombianos fugindo da guerra do narcotráfico... (SÁ AMADO, 2016)

Desde 2017 temos no Brasil um fluxo significativo de venezuelanos, adultos e crianças, que cruzam as fronteiras situadas no norte do nosso país, e no qual estão fugindo desesperados da fome, da hiperinflação e da miséria que assola o país Sul-Americano vizinho na atualidade. Segundo último relatório da ACNUR, no total, 33.866 pessoas solicitaram o reconhecimento da condição de refugiado no Brasil em 2017. Os venezuelanos representam mais da metade dos pedidos realizados, com 17.865 solicitações. Na sequência estariam os cubanos (2.373), os haitianos (2.362) e os angolanos (2.036). Os estados com mais pedidos de refúgio são Roraima (15.955), São Paulo (9.591) e Amazonas (2.864), segundo dados da Polícia Federal.

Estes imigrantes, na sua grande maioria, quando aqui chegam no nosso país pouco ou nulo conhecimento têm do idioma português. E, sendo assim, sentem a necessidade imediata de aprendê-lo. Assim como ressalva Sá Amado (2016), o ensino do português não é prioridade das esferas governamentais, estaduais ou municipais e ficam a cargo de organizações não governamentais (ONGs) e associações sem fins lucrativos (ASFL) quando não de pessoas que de maneira voluntária se sensibilizam com a causa humanitária.

Este artigo tem portanto a finalidade de relatar a experiência de um curso de extensão e voluntariado feito em parceria entre a Universidade Federal do Rio Grande do Norte (UFRN) e a ONG SOS Aldeias Infantis da cidade de Caicó-RN. O curso, chamado de SOS Português e Aldeias Infantis, teve em sua fase inicial a duração de 20 horas e ocorreu entre os meses de outubro e novembro de 2018. Quando nos referimos à fase inicial é porque existe Revista Extensão em Foco, nº 20, Jan./Jul. (2020), p. 31 - 44. 
uma grande probabilidade de que o mesmo volte a ocorrer em 2019, já que há interesse de ambas instituições envolvidas para que isto aconteça.

Como proposta para as nossas atividades tentamos ao máximo trabalhar atividades nas quais o vocabulário ensinado e os temas culturais abordados em sala estivessem contextualizados com ações e sentimentos positivos como encorajamento, persistência, tolerância - com a intenção de contribuir de maneira positiva não só com o aprendizado de português para estes alunos imigrantes, mas também de colocar em prática ações humanizadoras de linguagem que lhes trouxessem alguma motivação diante das tantas adversidades as quais se deparavam/deparam no nosso país. Assim como afirma Kfouri Kaneoya (2016) “em termos educacionais, ao ensinar uma língua estrangeira na atualidade se deve levar em consideração que há valores universais como a preservação da vida, da paz e da justiça.” Há outros autores que vão ainda mais além:

ouvir as histórias dos participantes e considerar as emoções como partes do processo de ensinar e aprender línguas são ações coerentes com esta perspectiva, já que emoções são propulsoras de mudanças e estão intimamente relacionadas ao ensino, que deve ser construído como um espaço de acolhimento e de pertencimento pessoal. (BARCELOS, apud KNOURI KANEOYA, 139)

Nesta perspectiva, nada mais adequado do que pensar que a formação do professor de línguas deva ir em uma direção que o convença do seu rol de agente humanizador, promovendo a sua autoestima e capacidade de dialogar para o bem, além de desenvolver a compreensão do seu papel de promotor da interculturalidade e da criatividade. Para Gomes de Matos (2014), “professores podem praticar simples ações positivas que os transformem em agentes humanizadores tais como conhecer as histórias, expectativas e desejos dos seus alunos." Outras ações como convidar os alunos para as interações em sala de aula, incentivar que trabalhos sejam feitos em grupos, reconhecer publicamente a importância de cada um no grupo, valorizar o conhecimento prévio dos seus discípulos sobre a língua, aprender e ensinar para a diversidade devem ser também pensadas pelo professor como prática frequente no seu processo de ensino.

Tomando como base esta Cultura da Paz e Linguística da Paz Aplicada foi que tentamos envolver todo o nosso projeto, inculcando - desde os professores voluntários aos alunos imigrantes inscritos no curso - valores como respeito e tolerância e ainda mostrandolhes desde uma ótica positiva a vantagem de acreditar em nós mesmos e de lutarmos por um mundo melhor.

Revista Extensão em Foco, nº 20, Jan./Jul. (2020), p. 31 - 44. 


\section{A Língua como ferramenta de inserção social e a designação do termo Português como Língua de Acolhimento}

A aprendizagem da Língua portuguesa é condição primordial na procura da inclusão social dos cidadãos estrangeiros que aqui chegam no nosso país. Segundo Leal \& Sánchez (2014), na Europa a aquisição de um nível A2 - segundo o Quadro Europeu Comum de Referência - é fator indispensável para que o imigrante possa aceder à cidadania, conhecer os seus direitos e deveres e até mesmo aceder à nacionalidade ou à autorização de residência permanente. Não ter conhecimento da Língua Portuguesa torna, portanto, o imigrante mais vulnerável e dependente, com dificuldades de inclusão e de se estabelecer no país de acolhimento.

Há autores que vão além e falam em identidades coletivas quando se referem à língua como fator de inserção social:

\footnotetext{
A permeabilidade de uma fronteira imaginada pressupõe que o indivíduo, portador de símbolos identitários coletivos, que dizem respeito à sociedade de onde vem, se aproprie de distintivos característicos da nova comunidade, aquela que está do outro lado da fronteira. Desta forma, é possível que ele transpasse as barreiras socioculturais e encontre o seu espaço na interseção com o outro. (PEREIRA \& COSTA 2016)
}

Uma das maiores necessidades vinculadas a estes coletivos de imigrantes que procuram o nosso país, relacionam-se principalmente com as destrezas da oralidade em que situações da vida quotidiana têm de serem aprendidas. A aquisição da competência comunicativa em Língua Portuguesa surge então como um fator que ajuda o imigrante no seu acesso à escolaridade, à vida laboral e aos restantes dos direitos assegurados pela sociedade.

Portanto, quando falamos deste ponto de vista social da língua ligado a situações de refúgio, falamos mais precisamente de língua de acolhimento. Segundo Pereira (2017), a expressão "língua de acolhimento" surge no contexto português após o aumento dos movimentos migratórios ocorridos em Portugal ao redor dos anos 2000, onde autores como Ançã (2003) defenderam o uso da designação através de uma tradução emprestada de outros como Lüdi e Py (1986). Para Amado (2017), o conceito de língua de acolhimento transcende a perspectiva linguística e cultural e refere-se também ao prisma emocional e subjetivo da língua e à relação conflituosa presente no contato inicial do imigrante com a sociedade de 
acolhimento, a julgar pela situação de vulnerabilidade que essas pessoas enfrentam ao chegarem a um país estrangeiro com a intenção de permanecerem nesse lugar.

Os estudos sobre português como língua de acolhimento, ou ainda, chamado língua de inclusão para outros autores, é de fato algo muito recente no Brasil e está a pleno vapor desde que começaram os pedidos de refúgio de sírios e haitianos no início desta década. Ao contrário do nosso país, em Portugal os estudos de língua de acolhimento já são uma realidade bem implantada nas universidades e há diversos estudos e pesquisas de grande peso neste país europeu. Além disto, o governo português - assim como em outros países da Europa, tem implementado durante as últimas décadas dois programas importantes que são o Português Língua não materna (PLNM) direcionado a estudantes do estudo regular e em idade escolar e o Português para todos (PPT), voltado exclusivamente para um público-alvo adulto.

Enquanto não temos a nossa disposição programas desenvolvidos por políticas de integração aqui no Brasil como os que já oferecem Portugal, vamos timidamente avançando em projetos de extensão e pesquisa nas universidades que atendem pelo menos de forma emergencial os principais problemas relacionados com esta grande novidade que é o ensino de português como língua de acolhimento. Entre os problemas que falamos, alguns estão relacionados com a falta de materiais específicos e a falta também de um maior embasamento teórico e acadêmico sobre o assunto, em que se discutam, por exemplo, enfoques para se trabalhar com o público-alvo. No próximo capítulo, falaremos sobre alguns detalhes do nosso projeto SOS Português \& Aldeias Infantis, que dadas as enormes dificuldades de um projeto iniciante como as que elencamos acima teve um enorme sucesso entre os envolvidos e nos deixou bastantes entusiasmados para prosseguir com uma segunda edição.

\section{O Projeto de Extensão e de voluntariado SOS Português \& Aldeias Infantis:}

Assim como muitas cidades do Brasil, a cidade de Caicó, no interior do RN, foi escolhida para um projeto federal de interiorização de acolhimento de venezuelanos que se encontram em situação de refúgio no país. Nesta cidade, um total de 68 pessoas, entre adultos e crianças, está sendo acolhido pela ONG SOS Aldeias Infantis - ONG que atua há mais de cinco décadas no Brasil e em vários países do mundo.

Nem todos os 68 venezuelanos participaram do nosso projeto. Alguns deles já se encontravam trabalhando e não puderam se inscrever nas nossas atividades, enquanto outros Revista Extensão em Foco, nº 20, Jan./Jul. (2020), p. 31 - 44. 
acreditavam já terem conhecimentos linguísticos suficientes por estarem a mais tempo no Brasil. ${ }^{2}$ Cabe dizer que a maior parte dos alunos inscritos na nossa atividade foram mulheres e a faixa etária das crianças assistidas foi de 3 e 4 anos de idade, pelo fato das crianças com idades maiores estarem matriculadas em escolas no mesmo horário do nosso curso. Tivemos na turma de adultos 21 alunos e a turma infantil foi composta por 16 crianças.

Sob nossa coordenação, o projeto intitulado SOS Português \& Aldeias Infantis teve no seu total a colaboração de 8 voluntários - onde todos eram alunos provenientes da Licenciatura em Letras do campi da UFRN de Currais Novos - deste total de graduandos, 5 eram oriundos da Licenciatura em Língua Espanhola, enquanto 2 eram oriundos da Licenciatura em Língua Portuguesa. Não houve precisamente uma seleção para atuar no dito projeto, sendo que o que foi feito para conseguir pessoal foi um anúncio nos corredores e salas da faculdade de Letras da UFRN, chamando pessoas interessadas em participar do mesmo como voluntárias. As sete primeiras pessoas que nos procuraram foram as que recebemos animados para compor o grupo de voluntários. Mal sabíamos que logo apareceriam dezenas mais de interessados e que infelizmente não teríamos como aceitá-los.

A escolha por não realizar uma seleção mais formal foi justamente por falta de tempo, já que tudo aconteceu muito rápido. A partir do momento que soubemos da vinda de imigrantes ao nosso estado do Rio Grande do Norte e que estes permaneceriam por um período de três meses, vimos que teríamos que arregaçar as mangas e trabalhar contra o tempo para que saísse algo satisfatório. Tivemos que escrever o projeto na plataforma SIGAA, levá-lo à plenária do Departamento para ser aprovado e consequentemente ser posto em execução, fazer cadastro das viagens como atividades de campo e além disto reservar um carro com capacidade para todos os voluntários viajarem. A cidade de Caicó fica a $86,5 \mathrm{~km}$ de Currais Novos, sendo aproximadamente uns 50 minutos de viagem.

As aulas do curso SOS Português \& Aldeias Infantis aconteceram todas as terças e quintas, entre os meses de outubro, novembro e começo de dezembro, com planejamentos semanais nas segundas-feiras, sempre com duas horas de duração. A maior dificuldade foi sem sombra de dúvidas as atividades realizadas com as crianças por não dispormos de um pedagogo no projeto que melhor nos orientasse em algumas atividades, como também encontramos na idade das mesmas uma labor extremamente complexa: antes de começar o projeto fomos informados pela coordenação da ONG que a idade das crianças seria entre 07 a

\footnotetext{
2 Muitos chegaram a ficar semanas ou meses em cidades brasileiras fronteiriças com a Venezuela.

Revista Extensão em Foco, nº 20, Jan./Jul. (2020), p. 31 - 44.
} 
10 anos, mas quando chegamos lá no primeiro dia de aula tivemos a surpresa de que a idade real era de 3 e 4 anos. Este mal entendido nos trouxe uma verdadeira dor de cabeça não só no primeiro momento mas nas primeiras aulas seguintes, onde tivemos que nos desfazer das aulas já planejadas e nos virar e improvisar atividades que melhor se encaixassem nesta faixa etária infantil. Quanto aos adultos, priorizamos atividades com estratégias comunicativas que melhor correspondessem à vida cotidiana dos envolvidos como atividades orais e escritas relacionadas com a solicitação de informações, como as de pedir conselhos, de como solicitar emprego, etc. Muitas das alunas matriculadas aproveitavam ainda a oportunidade e nos traziam atividades escolares dos seus filhos para que tirássemos algumas dúvidas que tinham ou também as ajudássemos a responder.

Não tivemos um material único a ser trabalhado no curso. Utilizamos algumas atividades do manual Avenida Brasil 1, da editora EPU, porém na maioria das vezes escolhemos elaborar o nosso próprio material utilizando materiais autênticos (textos jornalísticos, panfletos publicitários, músicas, etc) para uma melhor qualidade das nossas atividades em sala de aula. Embora evitássemos ao máximo trabalhar uma gramática que não estivesse contextualizada com os assuntos culturais planejados, foram muitos os questionamentos e solicitações por parte dos venezuelanos para que explicássemos certas regras gramaticais que muitas vezes não se relacionavam com as temáticas mostradas em sala.

Por falta de espaço mostraremos aqui apenas duas das muitas atividades realizadas em sala de aula para o grupo de venezuelanos de faixa etária adulta. Estas atividades foram segundo nossas observações e as que melhor tiveram interação de todos os alunos em sala.

\section{Exemplo de atividade 1:}

Em uma das aulas colocamos a canção $O$ Sol, grande sucesso no Brasil no ano de 2018 e que tem como autor e intérprete o cantor Vitor Kley. Esta canção, de celebração à natureza e que ao mesmo tempo dá margem a mais de uma interpretação (de que se o Sol poderia, por exemplo, ser uma pessoa na vida de quem declama a música) nos deu a possibilidade de trabalhar com ela através de mais de um caminho.

Primeiramente, questionamos com eles, os alunos, sobre o que acreditavam: se a canção era apenas uma oda ao Rei Sol ou se havia uma indireta do cantor a alguma pessoa amada. Depois das respostas, pegamos como base a primeira opção e lhes perguntamos sobre se gostavam de fato de dias ensolarados como os que se apresentavam na região e se as altas Revista Extensão em Foco, nº 20, Jan./Jul. (2020), p. 31 - 44. 
temperaturas na cidade de Caicó-RN eram parecidas com as das diversas cidades as quais eles eram oriundos. Iríamos ainda nesta mesma aula, em atividade posterior, falar sobre climas e temperaturas, então partindo através desta atividade prévia achávamos que íamos por um bom caminho.

Demos sequência à atividade e tomando como base a segunda interpretação da música, perguntamos se havia um "Sol" na vida de cada um dos alunos presentes, ou seja, se eles tinham um grande amor na vida e estavam dispostos a comentar com os colegas sobre quem era esta pessoa. Houve nesta parte da atividade muita descontração e ao mesmo tempo ouvimos narrações de histórias muito comoventes em sala, onde, por exemplo, alunos narravam a dura situação de haver deixado para trás os seus maridos/esposas na Venezuela e que, até então, mesmo já estando em situação de abrigo no Brasil, haviam mantido pouco contato com estes familiares. Houve um relato também de uma mãe que falou que o "verdadeiro Sol" da vida dela era sua filha que havia ficado no país vizinho, que por um simples motivo burocrático não havia conseguido trazê-la junto com ela e o seu outro filho ao Brasil. Vale ressaltar que em nenhum momento houve intenção de constranger ou forçar os alunos a falarem, tudo foi feito de forma espontânea e deixado claro, desde o princípio que eles eram livres para expor - ou não - suas histórias e emoções da melhor forma que achassem.

Aproveitamos ainda a canção para realizar uma atividade fonológica trabalhando o som da letra $\mathrm{v}$ bem presente na letra - assunto que eles já haviam até mesmo solicitado, dadas as dificuldades que tinham com este fonema. Na parte de vocabulário, ainda reforçamos o uso das palavras esquecer e precisar, que já haviam sido ensinadas em uma aula anterior.

O uso desta canção em sala teve um tremendo sucesso por parte dos alunos envolvidos e não foram poucas as vezes que os mesmos nos pediram para tocá-la novamente nas aulas durante o restante do curso.

\section{Exemplo de atividade 2:}

Outra atividade a qual tivemos bastante sucesso em realizar foi uma sobre elogios e qualidades, onde fizemos uma dinâmica de jogo no qual todos participaram. O objetivo de tal atividade era também, de um modo geral, a do curso, ou seja, a de promover o uso de uma linguagem humanizadora em sala de aula por meio da aprendizagem de expressões de elogio e encorajamento.

Revista Extensão em Foco, nº 20, Jan./Jul. (2020), p. 31 - 44. 
Começamos a aula através da pergunta: $O$ que é um elogio? Você já elogiou alguém hoje? Já foi elogiadola? Gosta de receber o elogio de alguém? Foi importante frisar a diferença entre o termo elogio e os termos hispânicos elogio, cumplido e piropo.

Dando sequência a atividade, perguntamos a eles que palavras ou expressões deveríamos usar quando alguém estivesse desanimado, triste, querendo desistir de alguma meta, etc. Logo colocaríamos algumas destas expressões no quadro branco e perguntaríamos quais eles gostariam que alguém os dissesse naquele dia e o porquê desta escolha.

Para encerrar e enfatizar ainda mais o conteúdo, colocamos em plaquinhas de cartolina o seguinte dizer incompleto "você é a pessoa mais que conheço. Aqui eles deveriam se dirigir a qualquer um dos colegas presentes, usando de qualidades positivas mostradas no quadro para completar a oração que lhes fora designada (antes tivemos de explicar o significado daquelas palavras que não conheciam: simpática, corajosa, resiliente, bonita, inteligente, esperta, paciente, animada, positiva, alegre, etc).

\section{Conclusões:}

Embora a questão tempo tenha sido a nossa pior inimiga no decorrer do projeto, tudo no final deu certo. Foram entregues certificados de conclusão em uma celebração que fizemos no último dia de aula (figura $2 \mathrm{em}$ anexo). A coordenadora do projeto, que no primeiro dia de contato com os venezuelanos teve de fazer toda a publicidade do curso em língua espanhola, teve o prazer de entregar-lhes os certificados em uma cerimônia toda falada em português. Os agradecimentos e ainda as queixas dos alunos sobre a curta duração do curso foi de fato uma grande satisfação não somente para a coordenação do projeto mas para todos os envolvidos no processo de uma forma geral.

Não foram poucos os venezuelanos que se queixaram do curto período do curso, já que lhes animava a ideia de aprender ainda mais a língua e também a de se "desconectar" dos problemas e da rotina a que estavam expostos aqui no Brasil. Segundo eles mesmos nos relatavam, as nossas aulas lhes serviam para momentos de desabafo sobre as suas angústias e também como momentos de descontração quando lhes levávamos alguma atividade de caráter mais lúdico. Na fala de uma aluna do nosso curso, ela saia a cada final de aula mais motivada e crente num futuro melhor pra ela e seus filhos, já que nós voluntários do projeto SOS Português e Aldeias Infantis lhes "enchíamos de pensamentos positivos e lhes fazíamos de vez em quando voltar a sorrir".

Revista Extensão em Foco, n 20, Jan./Jul. (2020), p. 31 - 44. 
$\mathrm{Na}$ falta de mais pesquisas sobre o ensino de português como língua de acolhimento no Brasil, por ser a imigração de refugiados uma realidade ainda recente, tivemos grandes dificuldades na hora de termos uma teoria mais consistente que nos desse um melhor ponto de partida. A proposta que colocamos em prática, a de uma Linguística da Paz vista tanto nos planejamentos semanais com os voluntários como também vista em todas as aulas do curso foi sem sombra de dúvida a melhor escolha que poderíamos ter feito para a realização e concretização do projeto que caminha com bastantes melhorias para a sua segunda edição.

\section{Referências bibliográficas:}

CANCLINI, N. G. Consumidores e cidadãos: conflitos multiculturais da globalização. 5.ed. Rio de Janeiro: UFRJ, 2005

EBERLAIN, E. ISHIHARA, T., BERGWEILER, C. Novo Avenida Brasil. Curso básico de Português para estrangeiros. Volumes 1,2 e 3. São Paulo: Editora E.P.U, 2017.

KFOURI KANEOYA, Marta Lúcia. Línguas estrangeiras como promotoras de práticas humanizadoras de linguagem: enfoque no português para falantes de outras línguas. In PFOL Português para falantes de outras línguas. Interculturalidade, inclusão social e políticas linguísticas. Campinas, Pontes Editores, 2016, pags. 137-160.

LACERDA DE SÁ, R. (org). PFOL Português para falantes de outras línguas. Interculturalidade, inclusão social e políticas linguísticas. Campinas, Pontes Editores, 2016.

LACERDA DE SÁ, R. \& RIBEIRO GUEDES, S. (org). PFOL Português para falantes de outras línguas. Materiais didáticos, formação de professores e ensino de gramática. São Paulo: Editora E.P.U, 2017.

LEAL, L. \& SÁNCHEZ, I. Português para todos: a aprendizagem da língua portuguesa como facilitadora da interculturalidade e da inclusão social e educativa. Revista Lusófona de Educação. Lisboa, no. 27, pags.143-157, 2014.

LIPOVETSKY, G. Da leveza. Rumo a uma civilização sem peso. Barueri: Editora Manole, 2016.

MOITA LOPES, L.P. Socioconstrucionismo: Discurso e Identidades Sociais. In: MOITA LOPES, L.P. (Org.). Discursos de Identidades. Campinas: Mercado de Letras, 2003, p. 1338

PARAQUETT, M. En defensa del abordaje multicultural em el aprendizaje de espanol lengua extranjera (ELE) In Actas del III simposio internacional José Carlos Lisboa de didáctica del español como lengua extranjera del Instituto Cervantes de Río de Janeiro, 2006, pags. 13-25.

Revista Extensão em Foco, nº 20, Jan./Jul. (2020), p. 31 - 44. 
PARAQUETT, M. "Perspectivas interculturais e relações internacionais na aprendizagem de Espanhol." In: BARBOSA, M.; MORAIS, C.F.; VIDAL, M.E.B.. (Org.). Teorias de linguagens: Pesquisa e ensino. 1ed.Campinas: Mercado de Letras, 2017, v. 1, p. 151-167.

PEREIRA, G. Língua de acolhimento e interação: a busca pela autonomia por pessoas em situação de refúgio no Brasil. Cadernos de Pós Graduação em Letras. São Paulo: v.17, n.1 pag.118-134 jan/jun 2017

PEREIRA, T \& COSTA, D. O Português como Língua de Inclusão de imigrantes haitianos no Rio de Janeiro. In PFOL Português para falantes de outras línguas. Interculturalidade, inclusão social e políticas linguísticas. Campinas, Pontes Editores, 2016, pags. 117-126.

SÁ AMADO, R. O Ensino de Português para refugiados: caminho para a cidadania. In PFOL Português para falantes de outras línguas. Interculturalidade, inclusão social e políticas linguísticas. Campinas, Pontes Editores, 2016, pags 69-86

SÃO BERnARDO, M. Português como Língua de Acolhimento. Um estudo com imigrantes e pessoas em situação de refúgio no Brasil. São Carlos, Universidade Federal de São carlos, 2016.

SERRANI, S. Discurso e cultura na aula de Língua: currículo-leitura-escrita. Campinas: Pontes, 2005.

\section{Anexo 1: Letra da canção O SOL}

Ô sol vê se não esquece e me ilumina

Preciso de você aqui

Ô sol vê se enriquece a minha melanina

Só você me faz sorrir

E quando você vem

Tudo fica bem mais tranquilo

Ô tranquilo

Que assim seja, amém

O seu brilho é o meu abrigo, meu abrigo

Revista Extensão em Foco, nº 20, Jan./Jul. (2020), p. 31 - 44. 
E toda vez que você sai

$\mathrm{O}$ mundo se distrai

Quem ficar, ficou

Quem foi vai vai

Toda vez que você sai

$\mathrm{O}$ mundo se distrai

Quem ficar, ficou

Quem foi vai vai vai

Quem foi vai vai vai

Quem foi

Ô sol vê se não esquece e me ilumina

Preciso de você aqui

Ô sol vê se enriquece a minha melanina

Só você me faz sorrir

E quanto você vem

Tudo fica bem mais tranquilo

Ô tranquilo

Que assim seja, amém

O seu brilho é o meu abrigo, meu abrigo

E toda vez que você sai

O mundo se distrai

Quem ficar, ficou

Quem foi vai vai vai

E toda vez que você sai

O mundo se distrai

Quem ficar, ficou

Quem foi vai vai vai

Quem foi vai vai vai

Revista Extensão em Foco, nº 20, Jan./Jul. (2020), p. 31 - 44. 
Quem foi vai vai vai

Ô sol vem aquece a minha alma

E mantém a minha calma

Não esquece que eu existo

E me faz ficar tranquilo

Vem aquece a minha alma

E mantém a minha calma

Não esquece que eu existo

E me faz ficar tranquilo

E toda vez que você sai

$\mathrm{O}$ mundo se distrai

Quem ficar, ficou

Quem foi vai vai vai

Toda vez que você sai

O mundo se distrai

Quem ficar, ficou

Quem foi vai vai vai

Quem foi vai vai vai

Quem foi vai vai vai

Anexo 2:

Figura 1

Revista Extensão em Foco, nº 20, Jan./Jul. (2020), p. 31 - 44. 


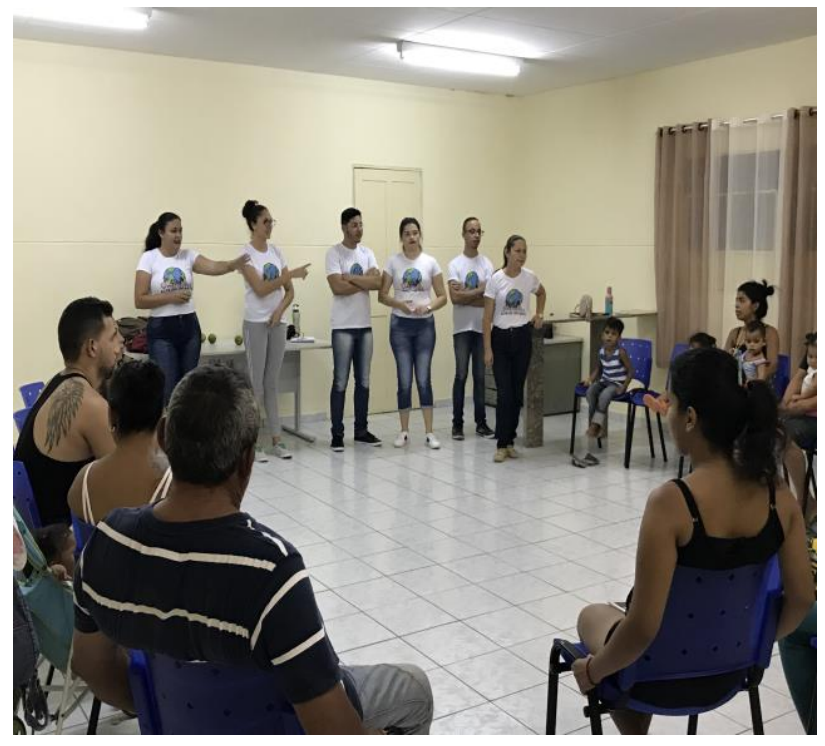

Voluntários colocando em ação atividade lúdica na primeira oficina do curso

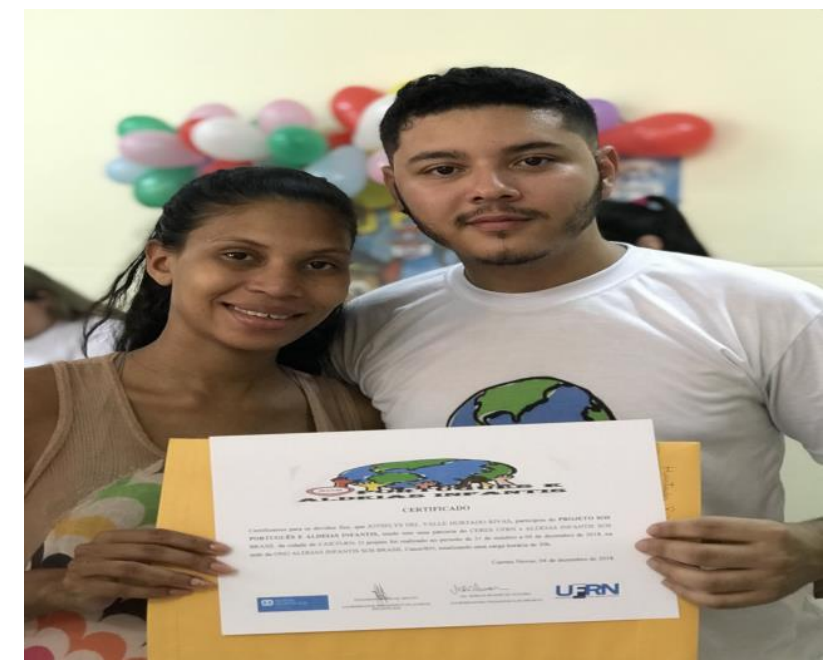

Figura 2:

Revista Extensão em Foco, nº 20, Jan./Jul. (2020), p. 31 - 44. 